\title{
STUDIES OF THE HEART AND CIRCULATION IN DISEASE; ESTIMATIONS OF BASAL CARDIAC OUTPUT, METABO- LISM, HEART SIZE, AND BLOOD PRESSURE IN 235 SUBJECTS
}

\author{
By ISAAC STARR, JR., J. S. DONAL, A. MARGOLIES, R. SHAW, \\ L. H. COLLINS, AND C. J. GAMBLE \\ (From the Laboratory of Pharmacology, and the Medical Clinic of the University \\ Hospital, University of Pennsylvania, Philadelphia)
}

(Received for publication February 21, 1934)

In a previous communication the results of duplicate estimations of cardiac output on 50 persons, the majority hospital patients in the basal condition, have been reported (1). The opportunity to extend this investigation rapidly was provided by the development, by Donal and Gamble, of a physical method for the estimation of ethyl iodide by means of its thermal conductivity in a katharometer (2). This improvement so increased the rapidity with which the cardiac output could be estimated, that about two hundred hospital cases, four hundred estimations of cardiac output, were added to the series with the expenditure of less time and effort than had been required to secure the results in the first fifty cases by the chemical technique. When the new series was combined with the old, over 200 cases were secured in which satisfactory estimations of basal cardiac output, metabolism, blood pressure, and pulse rate, had been made on resting patients 15 or more hours after the last meal; and in which orthodiagrams had been secured also. The analysis of these results forms the subject of this paper.

As soon as results, secured by any cardiac output method, are examined a difficulty appears which can best be set forth by an example. The average cardiac output of 31 healthy persons is 2.9 liters per minute per 100 pounds, that of 8 cases of anemia 3.2 liters; should the difference be considered significant or not? An estimation of the validity of differences is based on knowledge of the relative accuracy of the methods involved. One may try to ascertain the accuracy of a cardiac output method, when applied to man, by the agreement of duplicate estimations, and by comparison of the results with those obtained by other methods, preferably based on different physiological principles. But it should be emphasized that cardiac output procedures have not attained the position of those methods the accuracy of which can be tested by estimation of known quantities. Therefore, we have fallen back on another way of approaching the problem and have estimated the significance of our differences by statistical procedures. 
By this means normal standards have been established for various functions of the circulation: viz, the cardiac output per minute, per body surface (cardiac index) and per body weight; the cardiac output per beat (stroke volume); the arteriovenous oxygen difference; the work of the left ventricle per minute and per beat; and the relationship of these functions to the size of the subject and of his heart. Knowing the normal statistics, one is then in a position to decide whether the circulation in diseased conditions is significantly different.

But the plan of the investigation was not limited to the description of the circulation in common diseased conditions, a field in which considerable progress has already been made (3). It was also hoped to discover a physiological relationship by which the condition of the heart muscle could be ascertained. This has been found in the relationship between the heart's work and its size, an extension of Starling's Law of the Heart to clinical conditions. This criterion has provided a physiological estimate of the condition of the myocardium in the common clinical conditions to which our cardiac output method could be properly applied, and has permitted a clearer differentiation between disease of the heart and disease of the peripheral circulation in these conditions.

\section{METHODS}

All patients were lying at rest 15 or more hours after the last meal. Outpatients lay down for over an hour before the first estimation. Ward patients were brought to our room in bed or in a wheel-chair, and then lay down for $1 / 2$ hour or longer before starting the determination.

The use of the katharometer for the analysis of ethyl iodide has not introduced any material change in the conduct of the cardiac output estimation (4). We made a few minor changes during the course of the investigations in order to increase the margin of safety. The rebreathing bag was filled with air containing the concentration of ethyl iodide expected at equilibrium. In place of the old average distribution coefficient (6.1) for ethyl iodide in air and blood, we made use of the data of Cool, Gamble and Starr (5) and estimated the distribution coefficient from the subject's red blood count. The results of cardiac output estimations published before (1) were recalculated and appear in this paper slightly changed, $61 / 66$ and $61 / 64$ of the original value for men and women respectively. In cases of anemia, of diabetes, and in certain other instances, 34 cases in all, Dr. Cool determined the distribution coefficient of the subject's blood, and his result was utilized in calculating the cardiac output.

The estimations of basal metabolic rate were made by the analysis of expired air. In calculating the result the average value of the respiratory quotient was assumed, but we made use of the calculated quotient to discard a few estimations in which it was unreasonable. Pressure of work made us omit the duplicate estimation of metabolism, in many cases. The single determination was made during the second estimation of cardiac output. Therefore, when the relationship between the metabolism and cardiac output was studied the result of the second estimation has been used. In all other instances the two calculated cardiac outputs were averaged.

The graphic record of respiration was omitted, reliance being placed on reading the spirometer every minute and counting the respiratory rate. 
The heart volume was determined by means of the orthodiagraph, the silhouette area and anteroposterior diameter being determined. The volume was calculated by means of Bardeen's formula (6); 0.53 (silhouette area) $\%$. After the investigation had been completed we recalculated the heart volume of a majority of the cases according to the newer method of Kahlstorf (7); 0.63 (silhouette area $X$ maximum anteroposterior diameter). But we had not fulfilled the exact requirements of that author, our silhouette areas having been determined with the arms down while he specifies that the arms should be raised. A few experiments to determine whether this made much difference indicated that the silhouette area might be changed as much as 5 per cent. In any event there was not enough difference between the results of the Bardeen and Kahlstorf methods to influence the statistics. In the following discussion the method of Bardeen was employed in all cases in which the method of Kahlstorf is not specifically mentioned.

We have continued to make orthodiagrams with the patient standing. We would have preferred to estimate the heart size with the subject lying, and some difference in the two positions is to be expected (6). But, we became convinced that the higher diaphragm shadow in recumbent patients would so reduce the accuracy with which the cardiac silhouette could be determined, that we decided to utilize a position different from that in which the other data were secured.

The katharometer was tested 25 times, usually at intervals of 10 days, during the course of this investigation. When known dilutions of ethyl iodide were estimated under the conditions present in cardiac output determinations, it never failed to give satisfactory results. Minute leaks, introduced intentionally, could be detected at once by the behavior of the mercury pressure gauge. An accidental leak was encountered only once during these experiments.

The analyses pertaining to cardiac output were all performed by Donal, those concerned with metabolism by Shaw. The orthodiagrams were all made by Margolies. The selection of the patients was largely made by Starr and Collins; most of the cases came from wards under their care. Margolies selected a few from the Out-Patient Department. Starr, Collins or Gamble supervised the subjects during the determinations and made clinical observations.

The calculations incident to the statistical analysis were made by Starr and Donal, each checking the other. We are again indebted to Dr. W. C. Stadie for suggestions and criticism of this analysis.

\section{NOMENCLATURE AND METHODS EMPLOYED IN THE STATISTICAL ANALYSIS}

Of the articles on statistics consulted, that of Dunn (8) proved most useful, and the methods there described have been followed.

To facilitate the calculations, the data were converted into smaller units by selecting an arbitrary origin near the midpoint and dividing the range of values into ten or more class units. The computations were made from frequency distributions and class units, and then converted back into the original units.

Differences have been considered significant when the probability of their arising from the sampling is less than 5 in 100 . Throughout this paper the differences mentioned without qualification meet this test.

We have assumed that the relationships that we have studied were linear. The scattering of the data seemed too great to warrant any other method of procedure.

The term cardiac output has been employed to mean the output of one side of the heart per minute, as is the custom. The cardiac index has come to mean the cardiac output per minute, per square meter of body surface. The stroke 
volume is the cardiac output per beat. We have employed the term cardiac work to mean the work of the left ventricle per minute.

As the subjects varied greatly in size, from 85 to 265 pounds, the absolute values of the cardiac output, stroke volume, and cardiac work have little meaning. It has been the custom to compare these figures with the body surface area. For reasons which will be discussed later, we prefer to refer them to the body weight. For convenience of expression reference to the latter will be omitted from the text when the full term appears in the table under discussion.

In Table VI the capacity of certain cardiac cases to perform muscular work has been indicated by the nomenclature devised by the New York Heart Committee, viz.: Class I, no restriction of activity; Class IIa, slight restriction; Class IIb, marked restriction; Class III bed patient.

\section{SELECTION AND GROUPING OF THE CASES}

Patients with congestive failure, with advanced pulmonary abnormalities, with emphysema, or with fever were avoided. We have employed the criteria given before (1), failure to attain a basal metabolic rate, hyperventilation, etc., to eliminate 25 cases from the statistical analysis. The remainder have been divided into clinical groups shown in Table I. The diagnoses of the individual cases can be found in Table VI, except Numbers 1 to 50 which have been reported before (1), under the same numbers. The sex, age, height and weight of these cases, not given before, have been appended in Table VII. Tables VI and VII appear together at the end of this paper.

TABLE I

Arrangement of the clinical material

31 healthy persons

47 hospital patients with normal circulations

(14 cases of hypotension also in above 2 groups)

Normal circulation group 78 cases

28 cases of hypertension

7 cases of anemia

15 cases of hyperthyroidism

13 cases of neurocirculatory asthenia

6 miscellaneous cases

20 cases-Myocardial Disease Group

$\left\{\begin{array}{c}\text { Cases once in congestive } \\ \text { failure, now having } \\ \text { recovered compensation }\end{array}\right.$

8 cases of valvular disease with regular rhythm

12 cases of arrhythmia

A. 8 arrhythmic when tested

B. 8 in regular rhythm when tested

10 cases of coronary disease

5 cases of acute endocarditis

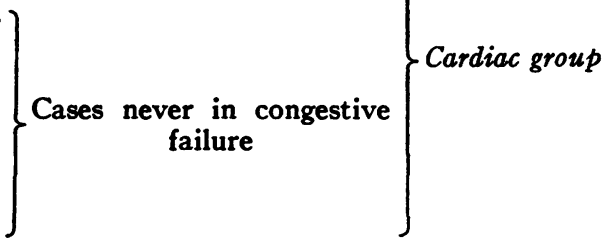

5 cases of aneurysm of the aorta 
Into the control group (Table I) we have gathered all cases believed to have normal myocardial function. These were selected more rigidly than in our previous study (1). In addition to those who had once been decompensated, all cases with any form of organic cardiac disease, serious arrhythmia, angina pectoris, or aneurysm were excluded. In addition, we thought it wise to omit 5 cases of hyperthyroidism, one case of anemia in shock, and one of myxedema, because of doubt concerning the condition of their hearts; and these cases have been starred in Table VI. On the other hand, we included cases of hypertension with cardiac enlargement in the control group, if their general condition was satisfactory.

Of the subdivisions of the control group, the healthy group was drawn from the faculty, students and technicians of the Medical School. The patients with normal circulation were taken from the hospital wards, a few older patients with slight sclerosis of peripheral vessels and three with peripheral vascular disease, but without other evidence of circulatory disease, were included. Together, these two groups form the normal circulation group. Cases with systolic blood pressure over $150 \mathrm{~mm}$. $\mathrm{Hg}$, except cases of hyperthyroidism and aortic regurgitation with large pulse pressure, have been included in the hypertension group. All cases having less than 70 per cent of hemoglobin were classified as anemias. The cases of hyperthyroidism were identified by their basal metabolic rate. The cases of neurocircu. latory asthenia were characterized by dyspnea and palpitation on slight exertion, and in addition several of the young women complained of transient cardiac pain, not definitely related to exertion. The diagnoses of the individual cases may be found in Table VI.

Of the cases in the normal circulation group, fourteen had a systolic pressure less than $100 \mathrm{~mm}$. These have been combined as the hypotension group, in order to contrast the findings with those of cases of hypertension.

The cardiac group consisted of cases with undoubted cardiac disease, but the conditions included were too diverse to warrant consideration of the group as a whole. The most important subdivision was the myocardial disease group, patients who, though now compensated, once had congestive failure. Therefore, there can be no doubt that they had serious myocardial disease at the time of the tests. The cases in the other subdivisions had never been decompensated and the clinical estimate of their myocardial condition did not seem sufficiently definite to base a classification upon it. For this reason, the chronic cases have been grouped according to their outstanding features: valvular heart disease, arrhythmia, or coronary disease (angina pectoris or occlusion). The cases believed to have active endocarditis at the time of testing were grouped separately, as were the cases of aneurysm demonstrable by $\mathrm{x}$-ray.

It is likely that medication, especially digitalis (14), influenced heart size and cardiac output in cases receiving it. We have made no attempt to correct for this variable, but, when cases were receiving such drugs, the fact has been set forth in Table VI. 


\section{RESULTS AND DISCUSSION}

Deviation of duplicate estimations of cardiac output made on the same day

In thirty healthy and intelligent subjects the average deviation of the duplicate estimations from their mean was 3.45 per cent. For the first 154 patients tested this deviation was 6.45 per cent. This is a significant difference. It cannot be attributed to training as the healthy group, with two exceptions, had had no previous experience with our apparatus. We attribute it to the unavoidable nervousness that the more ignorant subjects feel when undergoing an unusual experience. The results show that standards of variation, secured on intelligent subjects, cannot be applied directly to hospital patients. In the former the deviation of duplicate estimations will exceed 10 per cent only once in twenty times; in the latter 20 per cent will be exceeded once in twenty times.

\section{Deviation of estimates secured on the same subject on different days}

Our data on this important point has been presented in Table II. The individual results obtained on any day have been used to find that day's average. This figure has been used as the basis of studying variations from day to day, the intervals reaching a year in some cases. The mean deviation for the 15 subjects is 6.3 per cent. The expectation is that, when the results secured on two days are compared, they will deviate from their mean by less than 20 per cent in 19 cases out of 20 . But while some subjects (Number 48) are characteristically steady from day to day, and on the same day, others (Number 43) are far more variable both in basal cardiac output and metabolism; and this difference has persisted over the period of 7 years since our method was developed.

\section{Discussion of mean values}

The mean values of the various groups and the standard deviation of the data about the mean are shown in Table III.

Before these data (Table III) could be interpreted it was necessary to ascertain the effects of sex and age upon the cardiac output. This has been estimated on the 78 cases composing the normal circulation group. The average cardiac index for males and females was identical. In the period before 20 years the average cardiac index is higher than at any time later, after 50 it slowly declines but the number of cases was too small to demonstrate the significance of the difference (Figure 1). If the cardiac output per kilo is considered, the increase in the average before the age of 20 is still more striking. The general trend is very similar to changes of the basal metabolic rate with age and this curve, prepared by DuBois (9) has been appended to Figure 1. Therefore, our normal standards derived from a group of diverse ages are not applicable to persons under 20 years without correction. The changes in advanced age have not been sufficiently defined 
to make correction possible. All but 10 of our 235 subjects were over 20 years of age, and when these were omitted it made little difference to the averages, but considerable difference to some of the correlation coefficients. In the data to be discussed the cases under 20 years of age have always been included unless a statement to the contrary is made.

TABLE II

Basal cardiac outputs on the same subjects on different:days

\begin{tabular}{|c|c|c|}
\hline $\begin{array}{l}\text { Subject } \\
\text { number }\end{array}$ & Date and cardiac output & $\begin{array}{l}\text { Average devia- } \\
\text { tion of each } \\
\text { days average } \\
\text { about the mean }\end{array}$ \\
\hline 48 & $\begin{array}{l}\text { liters per minute } \\
\text { 2-13-28, 3.6; 3-13-28, 3.8, 3.7, 3.8; 3-17-28, 3.7, 3.6, } \\
3.6 ; 1-16-30,3.3,3.3 ; 4-30-31,4.2 ; 5-8-31,3.7 ; \\
3-18-32,3.5 ; 3-21-32,3.7,4.0,3.5,3.4 ; 3-22-32,3.9 \\
3.8,4.1,4.2 ; 9-25-33,3.8,4.0 ; 9-28-33,3.2,3.3 ; \\
1-31-34,3.9,3.9 ;\end{array}$ & $\begin{array}{c}\text { per cent } \\
2.8\end{array}$ \\
\hline 43 & $\begin{array}{l}3-8-28,4.9,4.5,3.8 ; 3-15-28,3.1,4.3,3.1 ; 4-24-28,2.8 \\
\quad 2.7,3.2 ; 1-18-30,4.5,4.9 ; 5-17-32,3.0,3.1 ; 11-3-33 \\
\quad 5.1,4.7 ;\end{array}$ & 9.2 \\
\hline 51 & $4-18-32,3.0,2.9,3.0,3.0 ; 12-6-33,4.1,3.9$ & 14.7 \\
\hline 52 & $4-21-32,5.1,4.1,4.2,4.3 ; 6-23-33,5.0,5.3 ;$ & 7.6 \\
\hline 53 & $5-10-32,3.7,3.9,3.7 ; 6-17-32,3.8,4.0$; & 1.8 \\
\hline 8 & $5-28-31,2.1,2.2 ; 3-28-32,2.1,2.2,2.6$ & 1.7 \\
\hline 151 & $3-14-33,2.6,2.5 ; 3-24-33,2.2,2.4$ & 5.2 \\
\hline 124 & $2-10-33,3.7,3.6 ; 3-25-33,3.1,3.0$ & 9.0 \\
\hline 152 & $3-17-33,4.5,5.1 ; 6-25-33,4.5,5.1 ; 10-30-33,3.9,4.2$ & 3.7 \\
\hline 220 & $6-23-33,3.3,3.8 ; 9-20-33,2.7,2.6$ & 14.5 \\
\hline 223 & $6-25-33,3.4 ; 10-26-33,4.5,4.4$ & 12.2 \\
\hline 227 & $10-27-33,3.2,3.4 ; 11-24-33,3.4,3.1$; & 0.8 \\
\hline $\mathbf{A}$ & $2-6-31,3.3,3.2 ; 7-15-31,3.1,2.9$; & 4.0 \\
\hline B & $3-4-31,2.0 ; 3-10-31,2.0,2.0$ & 0 \\
\hline \multirow[t]{2}{*}{ C } & $4-4-31,2.3 ; 4-6-31,2.4 ; 4-10-31,1.7$ & 6.8 \\
\hline & Average & 6.3 \\
\hline
\end{tabular}


TABLE III

Statistics concerning the heart and circulation under basal conditions Means (in Roman type)

Standard deviations about the means (in italics)

\begin{tabular}{|c|c|c|c|c|c|c|c|}
\hline & $\begin{array}{c}\text { Ap- } \\
\text { proxi- } \\
\text { mate } \\
\text { num- } \\
\text { ber of } \\
\text { cases }\end{array}$ & $\begin{array}{l}\text { Cardiac } \\
\text { output }\end{array}$ & $\begin{array}{l}\text { Cardiac } \\
\text { output }\end{array}$ & $\begin{array}{l}\text { Cardiac } \\
\text { stroke } \\
\text { volume }\end{array}$ & $\begin{array}{c}\text { Arterio- } \\
\text { venous } \\
\text { oxygen } \\
\text { difference }\end{array}$ & $\begin{array}{l}\text { Left ven- } \\
\text { tricular } \\
\text { work per } \\
\text { minute }\end{array}$ & $\begin{array}{l}\text { Left ven- } \\
\text { tricular } \\
\text { work per } \\
\text { beat }\end{array}$ \\
\hline & & $\begin{array}{l}\text { liters per } \\
\text { minute per } \\
\text { sq. meter } \\
\text { body surface }\end{array}$ & $\begin{array}{c}c c . \text { per } \\
\text { minute per } \\
\text { kgm. body } \\
\text { weight }\end{array}$ & cc. per kgm. & $\begin{array}{l}\text { cc. per } \\
\text { liter blood }\end{array}$ & \begin{tabular}{|} 
gram-meter \\
per kgm. \\
body \\
weight
\end{tabular} & $\begin{array}{l}\text { gram-meter } \\
\text { per kgm. } \\
\text { body } \\
\text { weight }\end{array}$ \\
\hline Healthy persons... & 31 & $\begin{array}{l}2.40 \\
0.55\end{array}$ & $\begin{array}{l}64.6 \\
15.3\end{array}$ & $\begin{array}{l}0.99 \\
0.28\end{array}$ & $\begin{array}{l}58.8 \\
14.0\end{array}$ & $\begin{array}{c}80.3 \\
18.5\end{array}$ & $\begin{array}{l}1.21 \\
0.29\end{array}$ \\
\hline $\begin{array}{l}\text { Patients with nor- } \\
\text { mal circulations. }\end{array}$ & 47 & $\begin{array}{l}2.15 \\
0.71\end{array}$ & $\begin{array}{l}61.6 \\
21.6\end{array}$ & $\begin{array}{l}0.86 \\
0.28\end{array}$ & $\begin{array}{r}63.9 \\
19.5\end{array}$ & $\begin{array}{l}74.8 \\
26.9\end{array}$ & $\begin{array}{r}1.06 \\
0.33\end{array}$ \\
\hline Anemia...$\ldots \ldots$ & 7 & $\begin{array}{l}2.52 \\
0.67\end{array}$ & $\begin{array}{l}71.5 \\
19.9\end{array}$ & $\begin{array}{l}0.83 \\
0.14\end{array}$ & $\begin{array}{l}48.2 \\
\quad 12.6\end{array}$ & $\begin{array}{l}81.1 \\
29.1\end{array}$ & $\begin{array}{l}0.97 \\
0.26\end{array}$ \\
\hline Hyperthyroid..... & 15 & $\begin{array}{l}2.90 \\
0.89\end{array}$ & $\begin{array}{l}81.6 \\
27.6\end{array}$ & $\begin{array}{l}0.80 \\
0.25\end{array}$ & $\begin{array}{l}70.1 \\
20.6\end{array}$ & $\begin{array}{r}113.6 \\
33.1\end{array}$ & $\begin{array}{l}1.14 \\
0.35\end{array}$ \\
\hline Hypertension..... & 28 & $\begin{array}{l}2.19 \\
0.81\end{array}$ & $\begin{array}{l}57.2 \\
28.2\end{array}$ & $\begin{array}{l}0.70 \\
0.29\end{array}$ & $\begin{array}{l}66.1 \\
20.0\end{array}$ & $\begin{array}{r}113.5 \\
59.1\end{array}$ & $\begin{array}{l}1.43 \\
0.65\end{array}$ \\
\hline Hypotension...... & 14 & $\begin{array}{l}2.39 \\
0.66\end{array}$ & $\begin{array}{l}68.4 \\
\quad 27.4\end{array}$ & $\begin{array}{l}0.89 \\
0.23\end{array}$ & $\begin{array}{r}65.7 \\
22.3\end{array}$ & $\begin{array}{r}73.2 \\
28.2\end{array}$ & $\begin{array}{r}1.04 \\
0.36\end{array}$ \\
\hline $\begin{array}{r}\text { Neurocirculatory } \\
\text { asthenia........ }\end{array}$ & 13 & $\begin{array}{l}1.70 \\
0.47\end{array}$ & ${ }^{50.0} 7.3$ & $\begin{array}{l}0.62 \\
0.19\end{array}$ & $\begin{array}{r}80.8 \\
19.3\end{array}$ & $\begin{array}{l}60.6 \\
15.6\end{array}$ & $\begin{array}{l}0.76 \\
0.28\end{array}$ \\
\hline $\begin{array}{r}\text { Patients recovered } \\
\text { from congestive } \\
\text { heart failure... }\end{array}$ & 20 & $\begin{array}{l}1.74 \\
0.41\end{array}$ & $\begin{array}{l}45.5 \\
10.1\end{array}$ & $\begin{array}{l}0.55 \\
0.18\end{array}$ & $\begin{array}{l}82.0 \\
20.6\end{array}$ & $\begin{array}{l}71.0 \\
22.5\end{array}$ & $\begin{array}{l}0.88 \\
0.33\end{array}$ \\
\hline Coronary disease. . & 10 & $\begin{array}{l}2.22 \\
0.85\end{array}$ & $\begin{array}{l}58.2 \\
25.1\end{array}$ & $\begin{array}{l}0.74 \\
0.26\end{array}$ & $\begin{array}{l}69.0 \\
27.9\end{array}$ & $\begin{array}{l}86.0 \\
39.7\end{array}$ & $\begin{array}{l}1.09 \\
0.45\end{array}$ \\
\hline $\begin{array}{l}\text { Valvular heart dis- } \\
\text { ease.......... }\end{array}$ & 8 & $\begin{array}{l}2.13 \\
0.37\end{array}$ & $\begin{array}{l}68.4 \\
22.9\end{array}$ & $\begin{array}{l}0.89 \\
0.31\end{array}$ & $\begin{array}{l}63.0 \\
23.0\end{array}$ & $\begin{array}{l}91.1 \\
36.4\end{array}$ & $\begin{array}{l}1.31 \\
0.49\end{array}$ \\
\hline $\begin{array}{l}\text { Formerly in arrhy- } \\
\text { thmia.......... }\end{array}$ & 8 & $\begin{array}{l}2.15 \\
0.45\end{array}$ & $\begin{array}{r}55.2 \\
18.3\end{array}$ & $\begin{array}{l}0.66 \\
0.20\end{array}$ & $\begin{array}{r}78.7 \\
18.3\end{array}$ & $\begin{array}{l}81.4 \\
26.7\end{array}$ & $\begin{array}{l}0.92 \\
0.31\end{array}$ \\
\hline Acute endocarditis & 5 & $\begin{array}{l}2.47 \\
0.40\end{array}$ & ${ }_{5.1}^{64.8}$ & $\begin{array}{l}0.85 \\
0.12\end{array}$ & $\begin{array}{l}64.5 \\
13.6\end{array}$ & $\begin{array}{r}107.0 \\
12.8\end{array}$ & $\begin{array}{l}1.05 \\
0.26\end{array}$ \\
\hline
\end{tabular}


The healthy group was composed of persons whose health and fitness were probably superior to the average and almost all were accustomed to laboratory procedure. The hospital patients with normal circulations were not only untrained, but suffering from the conditions indicated in Table VI,

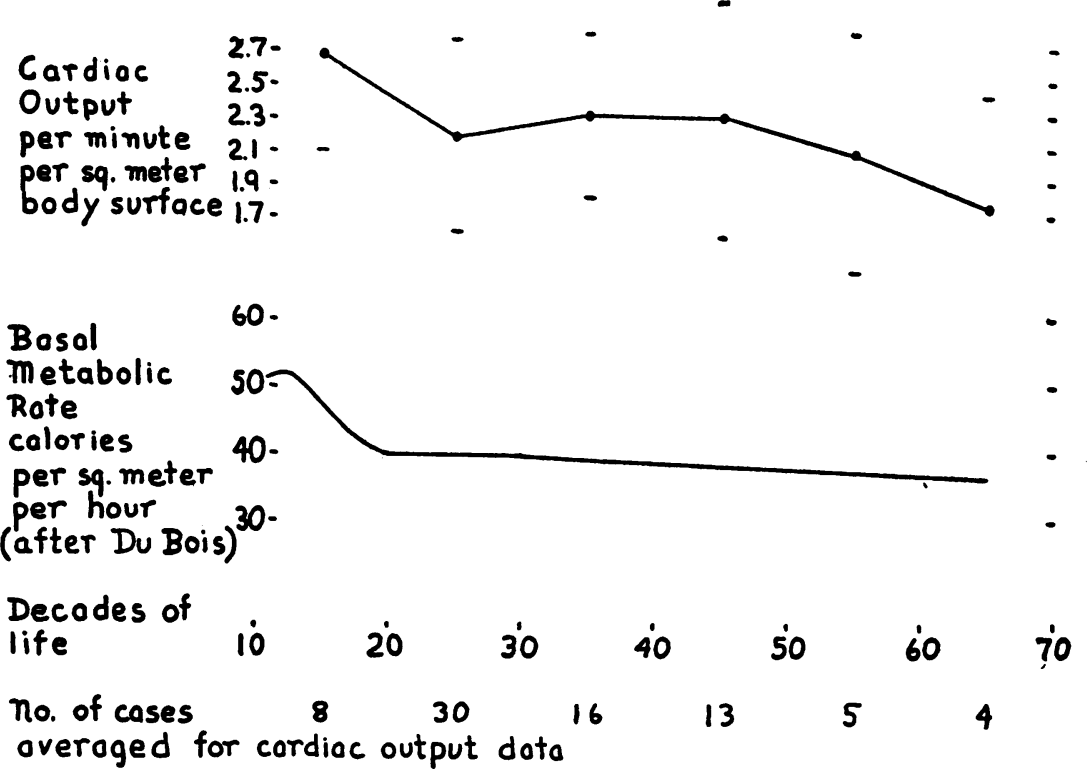

Fig. 1. Effect of Age on Basal Cardiac Output

The results obtained on persons in each decade of life have been averaged. The dots indicate the means of these groups, the dashes the standard deviation about the means. The curve showing the effect of age on basal metabolic rate (after DuBois) has been appended for comparison.

many were in poor physical condition. The former group averaged 5 years younger and 20 pounds heavier than the latter. In spite of these differences the healthy subjects had an average cardiac output, arteriovenous oxygen difference, heart work, and heart size which did not differ significantly from those of the hospital patients. But the average stroke volume and heart work per beat were smaller in the hospital cases. These differences were small and barely attained significance. Whether they demonstrate a real effect of intercurrent disease on the circulation or were merely due to increased pulse rate from nervousness in the more ignorant patients, we have no means of deciding. But it seemed evident that the results obtained on the hospital patients with normal circulations would make the better standard for comparison with those secured on other patients, so we have used these statistics as a basis for ascertaining differences from the normal. 
The anemic patients had an average hemoglobin of 50 per cent. They differed from the normal in that their arteriovenous oxygen difference was smaller. Their stroke volume was normal, and the pulse rate being faster, the average cardiac output was above normal, but we have not demonstrated that this difference is significant. This increased cardiac output in anemia has been demonstrated by others (3).

When the ethyl iodide method is employed in the investigation of hyperthyroidism, a difficulty presents itself. A slow lowering of basal metabolism often follows the administration of iodides to such patients, and the inhalation of ethyl iodide might depress the metabolism, and perhaps the cardiac output also, at the time the determinations were made (10). Seeking for such an effect, we compared the results of routine estimations made by the Benedict-Roth apparatus with those secured during the inhalation of ethyl iodide. The results indicated that the latter procedure had no immediate effect on the metabolism of our cases. This may have been due to the fact that all but two of them had been receiving iodide by mouth before the estimations were made, and the maximum iodide effect had been secured already.

The average basal metabolic rate of the hyperthyroid group was 45 per cent above the calculated normal. The group had a more rapid pulse rate, a larger cardiac output and a greater cardiac work than the normal. No other differences from the normal have been demonstrated to be significant. The increased cardiac output in hyperthyroidism is well known (3).

The cases of hypertension had large hearts which performed an increased amount of work both per minute and per beat and had a smaller stroke volume than the normal. In other respects they resembled the normal group. The cases of hypotension had circulations not significantly different from the normal, but their results showed a marked contrast with those secured in hypertension.

The results obtained in cases of neurocirculatory asthenia, though suggested in previous work (1), surprised us greatly. Although the symptoms occurred chiefly on exertion, the circulations at rest were highly abnormal. The average cardiac output, stroke volume, and heart work per minute and per beat were all far below normal. The arteriovenous oxygen difference was abnormally large, so these patients doubtless had a lowered oxygen tension in their tissues. Except for the size of their hearts, smaller than normal, their averages closely resemble those secured on patients with undoubted myocardial disease.

Of the cardiac group, those with undoubted myocardial disease, who were once decompensated, stand out. The averages show that these patients had an abnormally small cardiac output, stroke volume, and work per beat; an abnormally large arteriovenous oxygen difference, and very large hearts. More unexpected was the similarity of their average heart work with that of the patients with normal circulation. This may be interpreted 
as indicating that the methods of compensation for myocardial disease, cardiac enlargement, increase in rate, etc., sufficed to bring the work performed by the heart back to normal, but this was insufficient to restore the circulation to its usual level. This normal average work per minute is largely due to the presence of cases of hypertension in the myocardial disease group. If these are omitted the average is much lower.

In the coronary group are 7 patients diagnosed as having had coronary occlusion. The electrocardiograms showed characteristic changes (11). None was in an acute attack when the estimations were made. In four, the attack had occurred within six weeks and they had not yet left their beds. Two of these, Numbers 31 and 88 , died shortly after the determinations, and the necropsies showed both old and fresh infarcts in each. Two cases of angina pectoris are also included in the group, and three of the cases of occlusion had previously exhibited this symptom. The most interesting aspect of the group averages is the close agreement with the normal in all items except heart size. It would appear that the effect of the lesions, probably involving only a small fraction of the total myocardium, has been amply compensated by the slight cardiac enlargement, as far as can be judged from studies on the circulation at rest.

In cases in which valvular disease was the dominant finding, and which had never been decompensated, the average values of their resting circulations were never significantly below normal. Their hearts were larger than normal and this had apparently compensated for the valvular defect, as far as the resting circulation was concerned. In a few individuals the results were far below normal, and their future course will be followed with interest.

The cases, the outstanding feature of which was attacks of arrhythmia, and which were in normal rhythm when the test was made, form a homogeneous group. The average arteriovenous difference and stroke volume resembled that of the myocardial disease group; they were significantly different from the normals. Their hearts were larger than those of the patients with normal circulations, but the difference is not significant. The other means (Table III) are close to the normal.

The cases in arrhythmia when tested were too diverse clinically to warrant statistical analysis as a group, but the individual cases demand some comment. They included five cases in auricular fibrillation, three in paroxysmal tachycardia, and two in complete heart block. The first were under the influence of digitalis, and except for the large size of their hearts, the findings do not differ significantly from the normal, except in Case 55, who died within 6 months of the test. Two of the cases of paroxysmal tachycardia exhibited a highly abnormal circulation during the attack, but the third maintained his circulation within normal limits, and indeed he suffered little inconvenience. The two cases of complete heart block were characterized by a small output per minute in spite of the abnormally large stroke 
volumes. The most interesting finding in these cases was the extremely low basal metabolic rates, -40 and -52 per cent. These figures were so low that we suspected an error. But a duplicate estimation on Case 234 checked well, the respiratory quotients were normal in both cases, and no such low result was obtained on any other patient in this series. These cases might be thought of as having maintained a normal arteriovenous oxygen difference, and hence a normal oxygen tension in their tissues, by reducing their metabolic rate and so compensating to some degree for the deficient circulation.

The cases of active endocarditis, 4 with acute rheumatic fever and one with subacute bacterial endocarditis show averages which are not significantly different from the normal, except for the work per minute which was above normal.

A general survey of the averages (Table III) impresses one with the constancy rather than the variability of many physiological functions in disease. The average heart volume in the myocardial disease group differs from the normal by 115 per cent, but the average cardiac output and its related functions never differ from the normal by more than 36 per cent. Compared with the scattering of the data, the differences between the means seem small. The overlapping is so great that there seems little chance of developing a method to determine the normality of the heart of a given case by means of the cardiac index, cardiac output per kilo, stroke volume, or arteriovenous oxygen difference.

Figure 2 shows that, in some of the clinical groups, the greatest frequency coincides, not with the group's mean, but with the mean of the normal persons. The hypertension group is the most striking example of this tendency. This lack of the normal statistical distribution of the results indicates that the group has lost its unity. It permits us to think of it as consisting of two parts: first, patients who have maintained their heart's work at the normal value, by reducing their cardiac output below normal and sacrificing the oxygen tension in their tissues; and second, those who have maintained a normal circulation at the expense of cardiac hypertrophy and increased cardiac work (1). One might expect that cardiac failure would eventually supervene in the latter and that breakdown would occur elsewhere in the former group.

Our average values for the cardiac index and arteriovenous oxygen difference in the normal circulation group agree closely with those obtained in normal persons by other cardiac output methods (3).

\section{Discussion of relationships}

The ideal relationship to distinguish normal from abnormal myocardial function would be one which holds closely, not only for normal conditions, but also for those in which the circulation, but not the heart, is primarily affected. Therefore, taking relationships which were significant for per- 


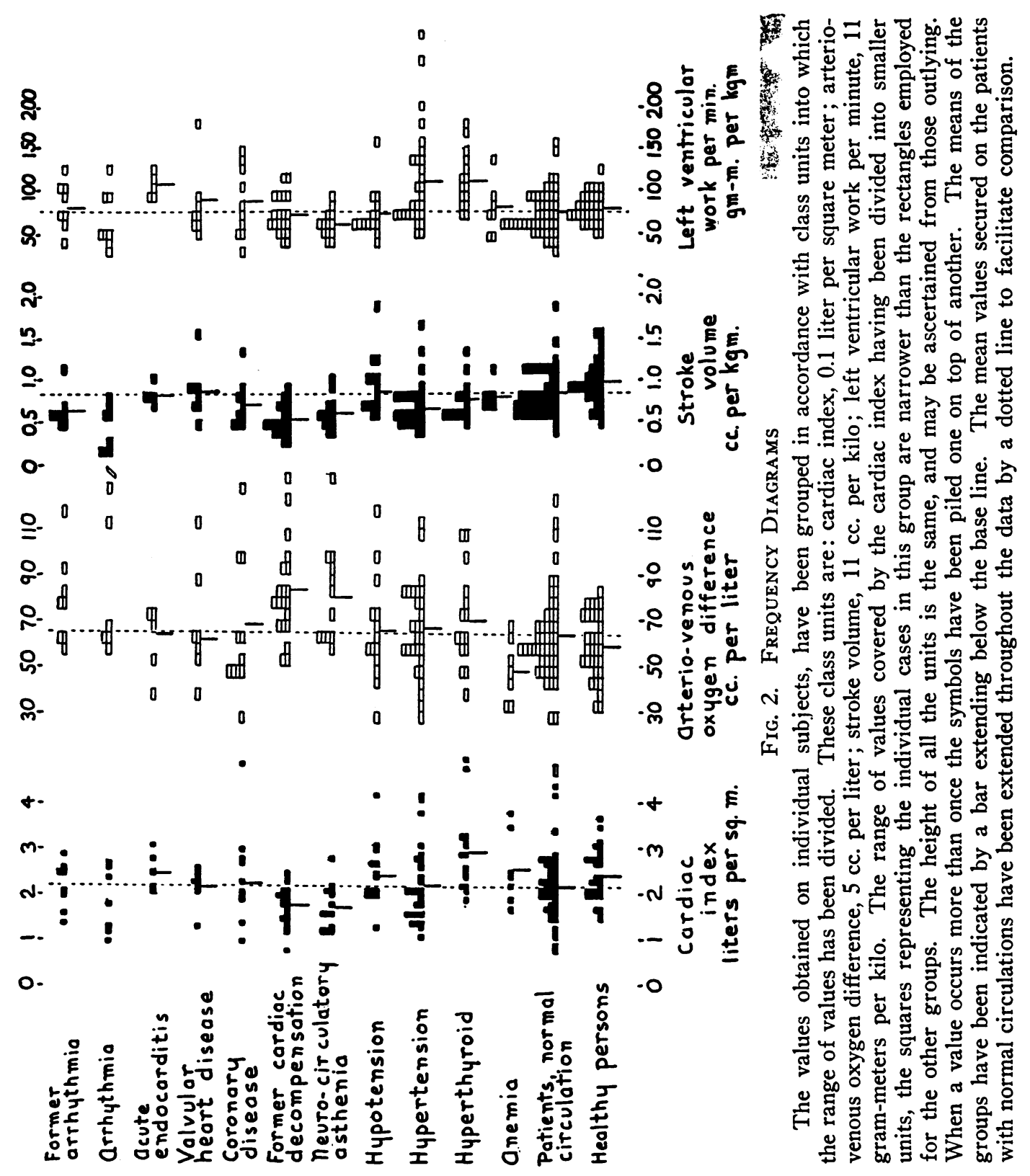


sons with normal circulations we planned to test them, first in cases of hypertension, and finally in the entire control group, which included those with normal as well as those with abnormal circulations.

TABLE IV

Correlation coefficients and their standard errors

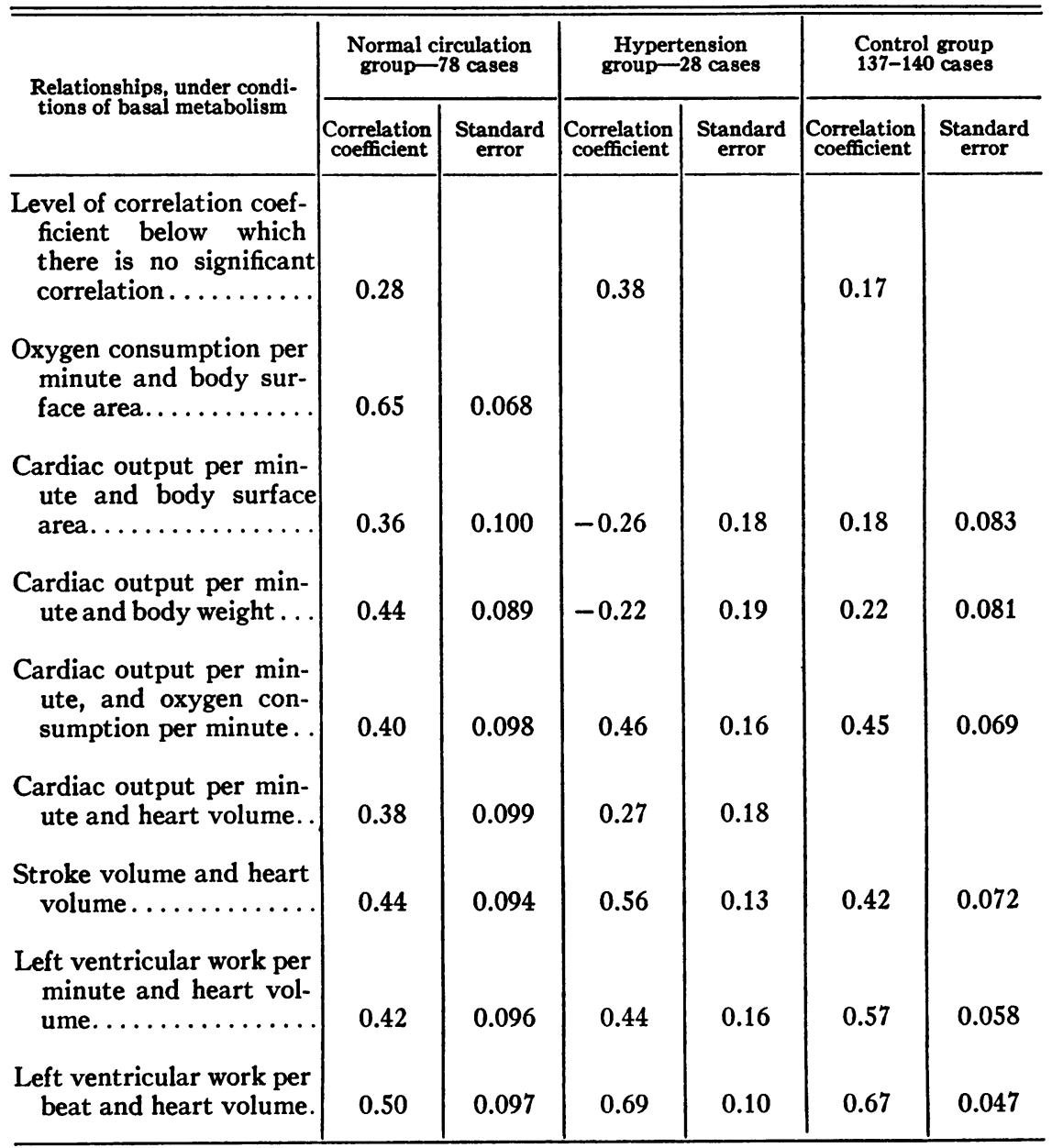

In the interpretation of the results (Table IV), and especially in the comparison with correlation coefficients obtained previously (1), several facts must be kept in mind. The correlation coefficient considered alone does not fully represent the degree of correlation of the data, i.e., a coefficient of 0.8 does not necessarily represent more perfect correlation than one of 0.7 . To compare the correlation one must consider not only the coefficient but also the number of cases in the series. This has been given (Table IV) as a level, varying with the number of cases, below which there 
were more than 95 chances in 100 that there was no correlation at all (12). In Table IV we have also given another expression based on the coefficient and the number of cases, the standard error of the correlation coefficient. If the coefficient is twice its standard error, the probability of the data being associated is 95 in 100, and this is the usual test of significance. If this ratio is 3 to 1 , this probability is over 99 in 100 . Thus the degree of correlation of the data may be ascertained by comparing the coefficient with its standard error. When these facts are kept in mind it becomes evident that, although the coefficients given in Table IV are sometimes lower than those obtained before (1), the evidence for the validity of the relationships has been greatly strengthened by the addition of the new data.

Basal metabolic rate and body surface area. This relationship is well known. In our subjects with normal circulations its correlation coefficient is $\mathbf{0 . 6 5}$. This, nine times its standard error, indicates a high order of association. It will be convenient to compare the other relationships with this well known one, and for convenience of expression, it will be referred to as the basal metabolic relationship hereafter.

Basal cardiac output per minute and body surface area. This is generally known as the cardiac index, and it is the usual method of reporting the results of cardiac output estimations. In normal persons it easily passes the test of significance; therefore, this conception is valid, but the correlation is far less than in the basal metabolic relationship. When persons under 20 years of age are omitted, the correlation in the normal circulation group is improved, from 0.36 to 0.41 , but it is still significantly smaller than in the basal metabolic relationship. Among cases of hypertension there is no correlation between cardiac output and body surface. In the whole control group, which includes the cases of hypertension, the correlation is barely above the level of significance. Therefore, the cardiac index is likely to prove a poor tool for the detection of heart disease. It does not distinguish disease of the heart from that of the circulation.

Basal cardiac output per minute and oxygen consumption. The quotient of these items gives the arteriovenous oxygen difference, and its importance has been properly emphasized (3). In normal persons the correlation is about the same as the preceding, it is much inferior to the basal metabolic relationship. Unlike the cardiac index, omission of the cases under 20 years of age has but little effect, and also, it holds for cases of hypertension. Its correlation is far superior to that of the index in the control group, attaining a value which, while considerably lower, is not significantly different from the basal metabolic relationship. Therefore, we regard this relationship as better and more fundamental than the cardiac index. An additional reason for this belief follows.

Partial correlations in the preceding relationships. Having calculated the correlations for the three interlocking relationships: oxygen consumption and body surface area, cardiac output and oxygen consumption, and 
cardiac output and surface area for the normal circulation group, it is possible to make use of the statistical device known as partial correlation (8). This permits holding one of the variables constant by mathematical means and studying the resulting effect on the relationship between the other two. Thus, if the oxygen consumption is held constant we find that the partial correlation coefficient between the cardiac output and body surface area is 0.012 , i.e., there is no significant correlation between them. Obviously, therefore, the cardiac output in normal persons is related to the body surface only because it is related to the oxygen consumption which in turn is related to the surface area. If a group of patients could be secured with identical oxygen consumptions we predict that their cardiac outputs would not be related to their surface areas at all.

Cardiac output per minute and body weight. This proved to have a coefficient considerably higher than the cardiac index but the difference, though suggestive, is not statistically significant. I ike the index, this relationship is different for persons under 20 years of age, the correlation in the normal circulation group improving from 0.44 to 0.50 when such cases are omitted. In Table III it will be seen that the mean cardiac output per kilo, of the healthy group, is closer to that of the hospital patients with normal circulations, than is the mean cardiac index. None of these differences are statistically significant; therefore, we are not in a position to decide definitely whether body weight or surface is preferable. But what evidence we have suggests that cardiac output should be compared with body weight rather than surface. Neither relationship holds well among the cases with abnormal circulation, neither can be used to detect cardiac disease.

Stroke volume and heart volume also output per minute and heart volume. In the normal circulation group these relationships have a correlation quite similar to the cardiac index. The former has a higher correlation in the hypertension and control groups. Both are inferior to the basal metabolic relationship.

Left ventricular work per minute and heart volume. In the control group this relationship is superior to those involving cardiac output, but, being inferior to that which follows, although not significantly so, it needs little discussion.

Left ventricular work per beat and heart volume. This is obviously the most interesting relationship that we have discovered. Among the patients with normal circulation it has the highest correlation except for the basal metabolic relationship. The differences in this group are not significant, but they become so as soon as the relationships are tested against patients with abnormal circulations. Under these conditions this relationship holds so well that its superiority over the others is very obvious. Indeed, in the control group, its coefficient is higher than that of the basal metabolic relationship, but the difference is not significant. This confirms 
our previous conclusion (1). It demonstrates that the basal work per beat of the normal heart is a function of its size, an extension of Starling's Law of the Heart (13) to clinical conditions.

When the heart volumes were calculated by the method of Kahlstorf instead of that of Bardeen the correlation of this relationship in the control group remained the same.

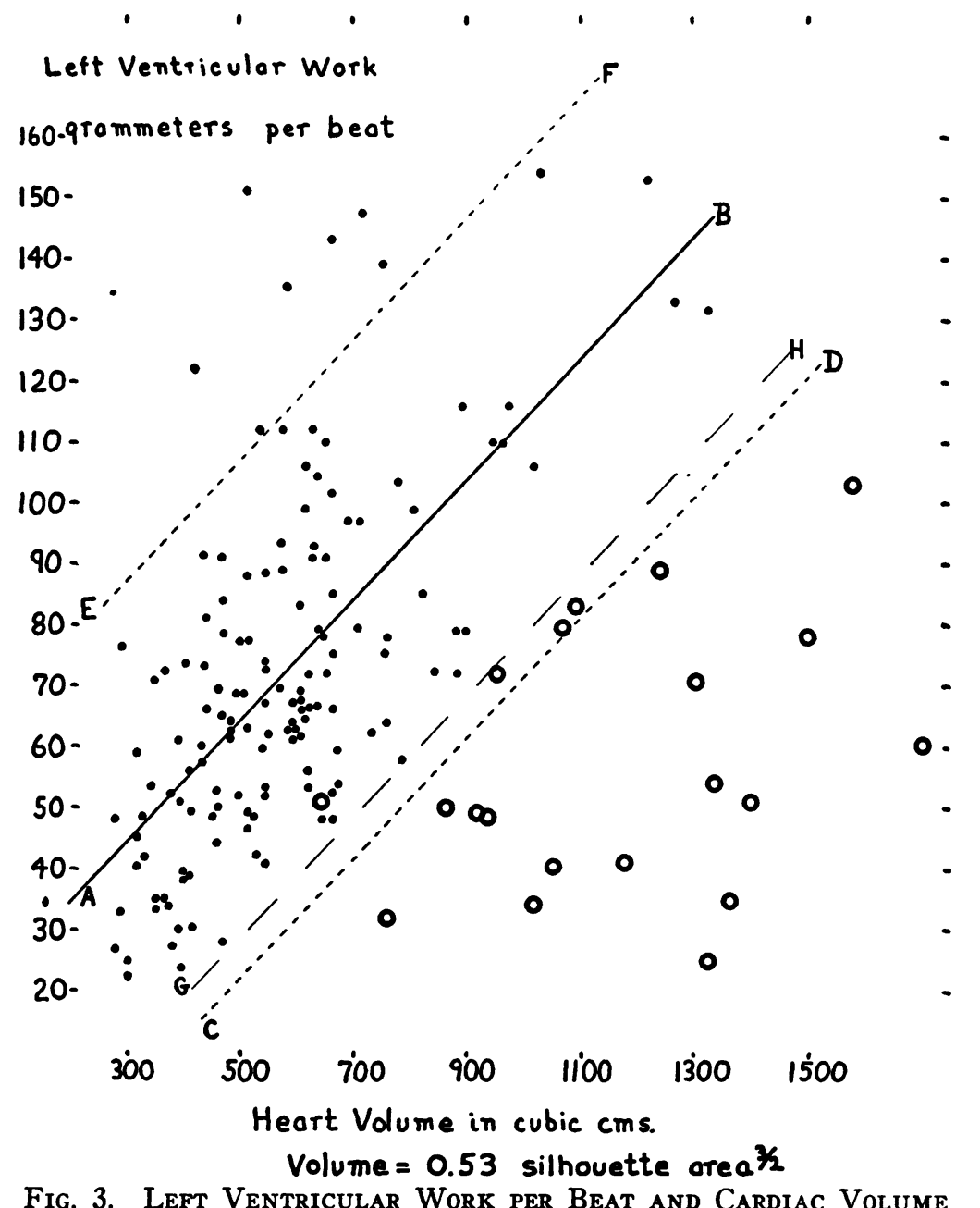

Each symbol represents the average of duplicate estimations. The dots indicate the values obtained in the control group. The solid line AB is the calculated best line for this group (the regression of heart work on volume). Lines $\mathrm{CD}$ and EF have been placed at a distance of twice the standard deviation about $A B$. Therefore, if any result falls to the right of $C D$ the probability of its differing from the normal is about 97.5 in 100 . The probability that a value falling to the right of GH differs from the normal is 95 in 100 . The circles indicate the values obtained on persons who had formerly had cardiac decompensation. 
Figure 3 shows the relationship between the left ventricular work per beat and heart volume for a large part of the data. The line $A B$ is the calculated best line for the control group, the regression of work on volume. The lines $\mathrm{CD}$ and $\mathrm{EF}$, placed at a distance from $\mathrm{AB}$ of twice the standard deviation about the regression line, would enclose about 95 per cent of all similar "control" cases. Therefore, the probability is about 97.5 in 100 that any result falling to the right of this area was secured from a case with abnormal myocardial function. It will be seen at once that the great majority of results, secured on persons who were once decompensated, lie well outside the normal zone. A few have attained the edge of it, but with one exception their chances of belonging to the normal group are less than 5 in 100.

This relationship in different clinical conditions can be further studied (Figures 4 and 5). The lines defining the statistical limits of the control group, shown in Figure 3, have been left in place. The cases omitted from the control group because of the fear that they were on the road to myocardial failure have been circled. It will be seen that in some cases our fears were groundless, but the majority of the values omitted are near the lower limit of the normal range.

The results on cases of hypertension had a poorer correlation than that found before (1), but the difference is not significant. This was chiefly due to three cases with small hearts doing large amounts of work. One of these cases was readmitted to the hospital three months after the test. During the interval the heart had doubled in size and marked hypertrophy was demonstrated at autopsy, the weight being twice the normal. Therefore, the increase of work preceded the enlargement in this instance.

Almost half the cases of thyroid disease gave values which lay close to the lower limit of normality. This is consistent with the well known frequency of cardiac complications in these cases.

Cases of functional heart disease and anemia gave results within normal limits.

We were surprised to find that numerous cases of coronary infarction, two of them later proved to be so at autopsy, gave values near the middle of the normal range. But we made no tests during the period of acute symptoms when a very different result might have been attained. Several cases of angina pectoris were also normal. This has been discussed when the means of this group were considered. The cardiac work-size relationship cannot be used to detect this type of cardiac disease.

The values secured in cases of arrhythmia are also shown in Figure 5. When the same patient was tested in both abnormal and normal rhythm, the results are joined by lines. While some of the values are entirely normal, others are close to the lower limit, and some far outside. The most divergent case died within six months. 
Most of the cases of aneurysm gave abnormal values. Perhaps the myocardium had been involved in the luetic process in these cases.

The cases of valvular heart disease who had never been decompensated gave values which fell partly within, partly without the normal. The latter may be thought as being on the road to decompensation; time will tell.

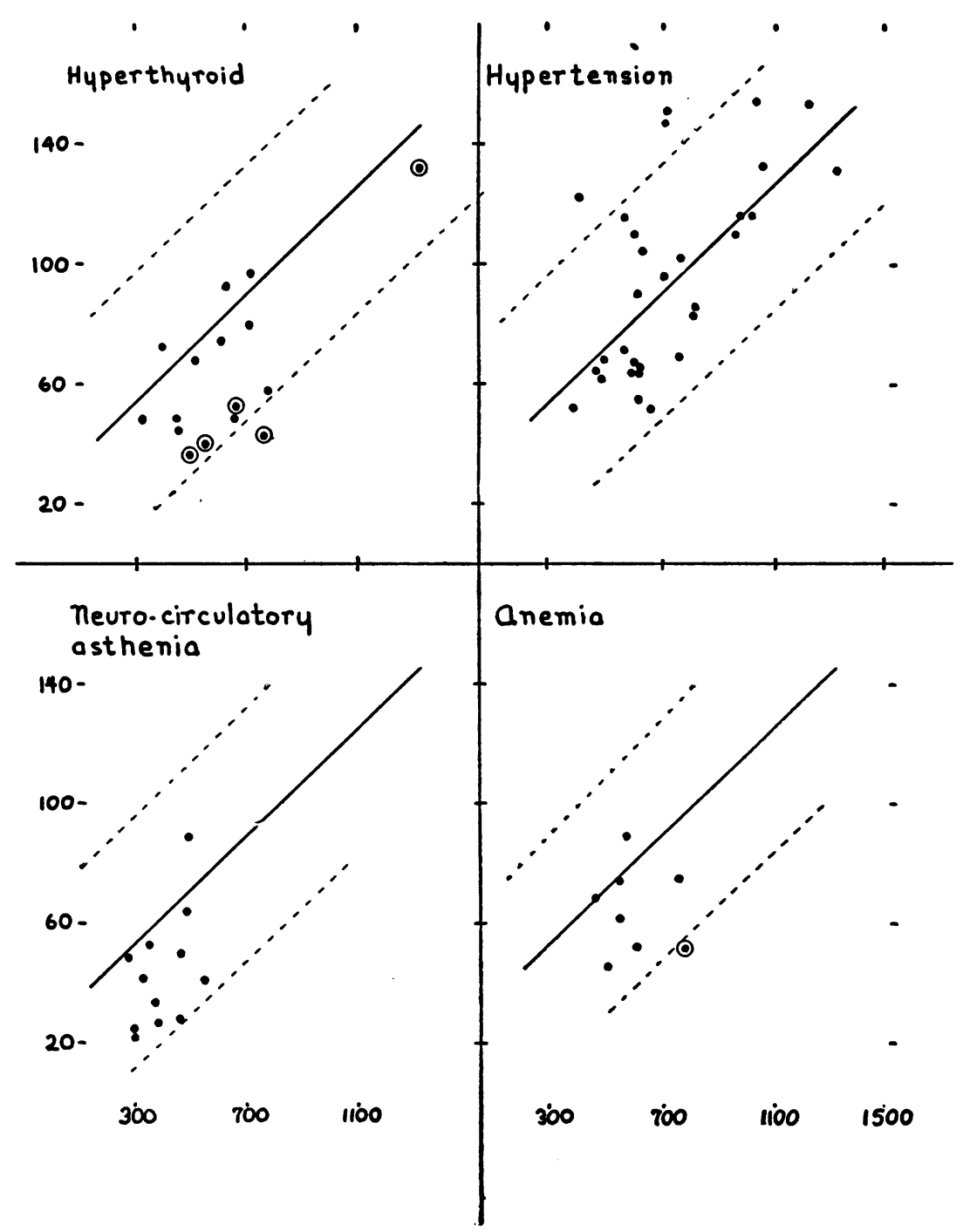

Fig. 4. Heart Work-Volume Relationship in Cases of Circulatory, but not Cardiac Disease

The coordinates are heart work per beat and heart volume as in Figure 3. The lines pertain, not to the values here recorded, but to the whole control group, as in Figure 3; they define the normal range of values. The dots representing values obtained in certain cases, in which clinical criteria made us doubtful concerning condition of the heart, have been circled. 
Detection of myocardial abnormality by means of the cardiac workcardiac size relationship. To determine the normality of a given case according to the newer statistics, one would insert the results into the following equation: 0.052 (cardiac silhouette area in sq. cm. $)^{3 / 2}-(\mathrm{L} . \mathrm{V}$. work per beat in gram meters) $=\mathrm{K}$.

If $\mathrm{K}$ is greater than 27 , the chances that there is abnormal myocardial function are about 97.5 in 100 . If $K$ is greater than 20 , the chances of

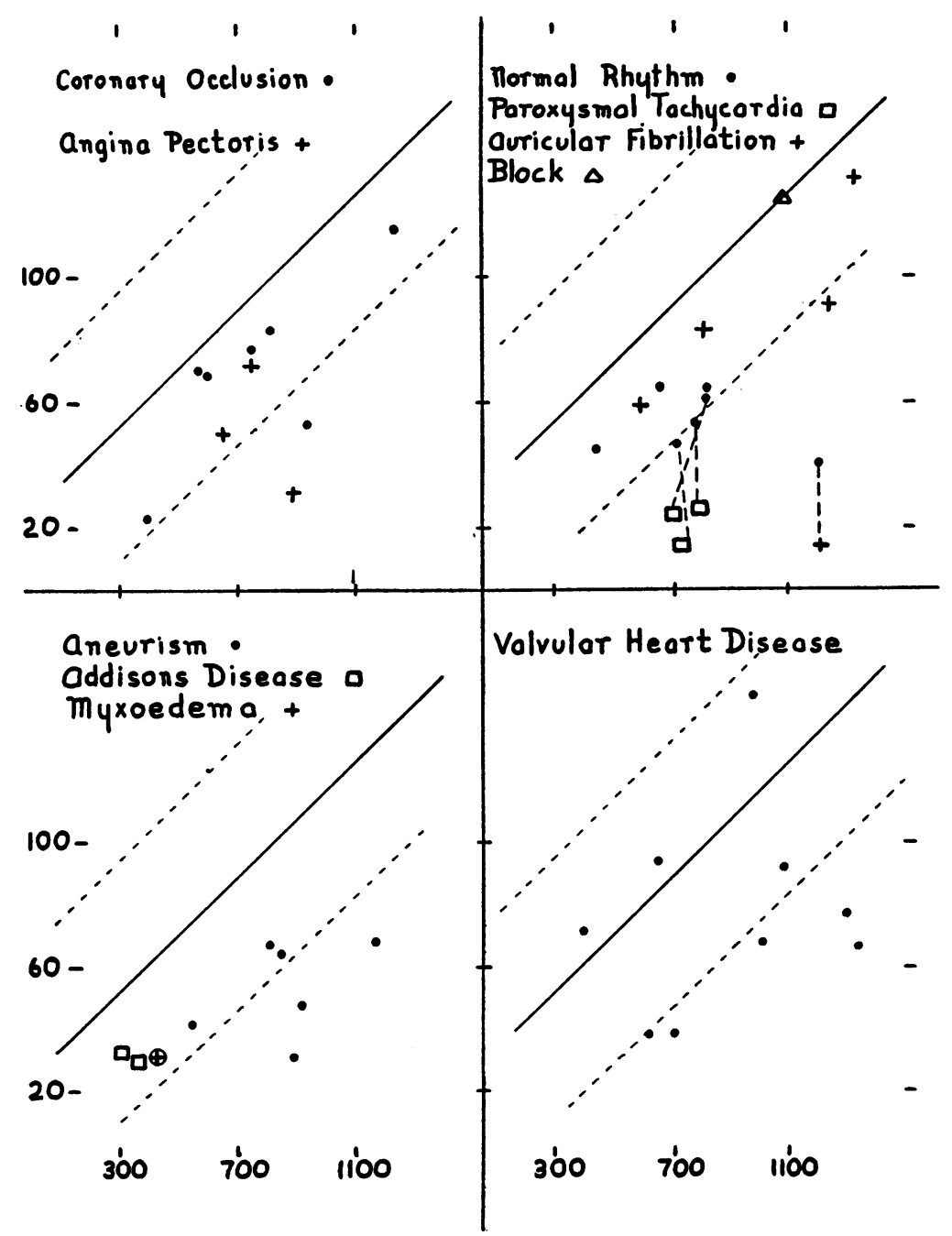

Fig. 5. Heart Work-Volume Relationship in Cases of Cardiac Disease

A few miscellaneous cases have been included also. Coordinates and lines as in Figure 3 and 4 . The values obtained in the same subject during an attack of arrhythmia and in normal rhythm have been connected by broken lines. 
abnormality are 95 in 100; if greater than 12 the chances are 90 in 100. The 95 in 100 probability $(K=20)$ divides the cases with undoubted myocardial disease from the control cases in our data, only one of those once decompensated having attained the normal range.

The data obtained in the normal circulation or hypertension groups may likewise be used to define normal myocardial function, but the statistical limits do not divide the normal from the abnormal cases quite as cleanly as the equation given above. The slopes of the best lines of these three groups are very similar and the deviation of the data about them is identical (Table V). This similarity emphasizes the fundamental nature of the relationship between heart work per beat and heart size.

\section{GENERAL DISCUSSION}

Our results indicate that the relationship between basal cardiac work and heart size provides a means of defining normal myocardial function and detecting that which is abnormal. This confirms the conclusion of a previous communication (1). The limitations of this means of detecting cardiac abnormality, which were set forth before (1), still hold. Many cases of coronary occlusion or of angina pectoris cannot be distinguished from the normal. In spite of this limitation, it is of interest to apply this criterion of cardiac normality to the conditions which we have studied.

Certain other findings, especially the arteriovenous oxygen difference, may be thought of as demonstrating the condition, not of the heart, but of the general circulation. Since it has been difficult to distinguish between circulatory conditions due primarily to trouble with the heart and those due to trouble elsewhere in the circulation, it is of interest to compare our findings with certain common clinical conceptions.

By our criteria, neurocirculatory asthenia, although often known as " functional heart disease," is shown to be characterized by normal cardiac function but an abnormal circulation. Reflecting on this situation the question might be asked whether the normal heart, confronted by such an abnormal circulation, would not increase its output until the arteriovenous oxygen difference was restored to normal; and whether its failure to do so should not be considered evidence that the heart was abnormal. According to our present knowledge of cardiac physiology this should be answered in the negative. The heart's output, and indeed its work also, is limited by the amount of blood returned to it through the veins. If this is inadequate, no effort on the part of the heart can increase the circulation.

In patients with low exercise tolerance, from either organic or functional heart disease, the circulation at rest has been believed to be normal. Our results show that, on the contrary, the average resting circulation of such patients is distinctly abnormal.

The clinical conception that patients, once in cardiac decompensation, 


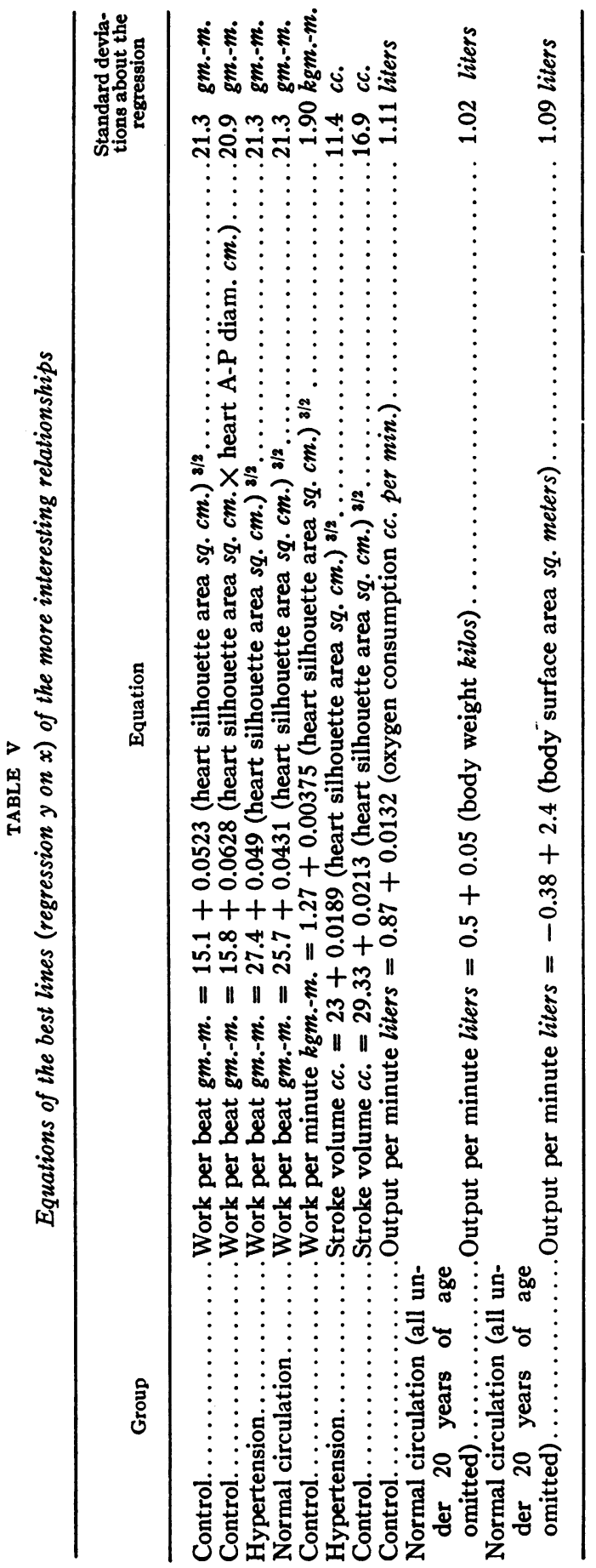


never completely recover from it, is in accord with our results. The one patient (Number 90) who appears to have regained normal myocardial function (Figure 3) was in congestive failure only during two short attacks of auricular fibrillation. The majority of these cases have adapted themselves to a condition in which the average oxygen tension of their venous blood, and hence of their tissues, is considerably below normal.

The foregoing discussion has been presented from the point of view that the relationship between cardiac work per beat and heart size is of greater importance than that between work per minute and heart size. The latter also separates cases who have once been decompensated from the control group, but there is more overlapping than when the former relationship is employed. Obviously, persons with abnormal pulse rates will be judged differently by the two methods, and in certain instances the latter might be a better test of normality. The final decision between them need not yet be made. The figures given in Table $\mathrm{V}$ define the normal range of the work per minute-heart size relationship in our data and permit the placing of individual results with regard to it.

\section{SUMMARY}

Duplicate estimations of cardiac output together with determinations of metabolism, blood pressure and pulse rate have been performed on 31 healthy persons and 204 hospital patients under conditions of basal metabolism. Orthodiagrams were secured also. The results have been subjected to statistical analysis.

The cases studied included patients with diseases not effecting the circulation, with hypertension, anemia, hyperthyroidism, neurocirculatory asthenia, valvular heart disease, various types of arrhythmia, coronary disease, acute endocarditis and aneurysm; also patients who had recovered from congestive heart failure. Acute cardiac decompensation, advanced pulmonary disease, and the febrile diseases were not studied.

The condition of the circulation in the various forms of disease has been described and compared with the normal. The most unexpected finding was that the average basal circulation in cases of neurocirculatory asthenia was very abnormal.

We have sought for relationships by which the condition of the heart muscle might be ascertained. Among normal persons, and patients with normal hearts but abnormal circulations, the relationship between heart work per beat and heart size holds more closely than any other studied. In cases who have been once decompensated this relationship is abnormal almost without exception. Therefore, we believe that it may be used to define normal myocardial function and to detect myocardial disease. Charts and equations are submitted by which the normality of any case can be decided. 


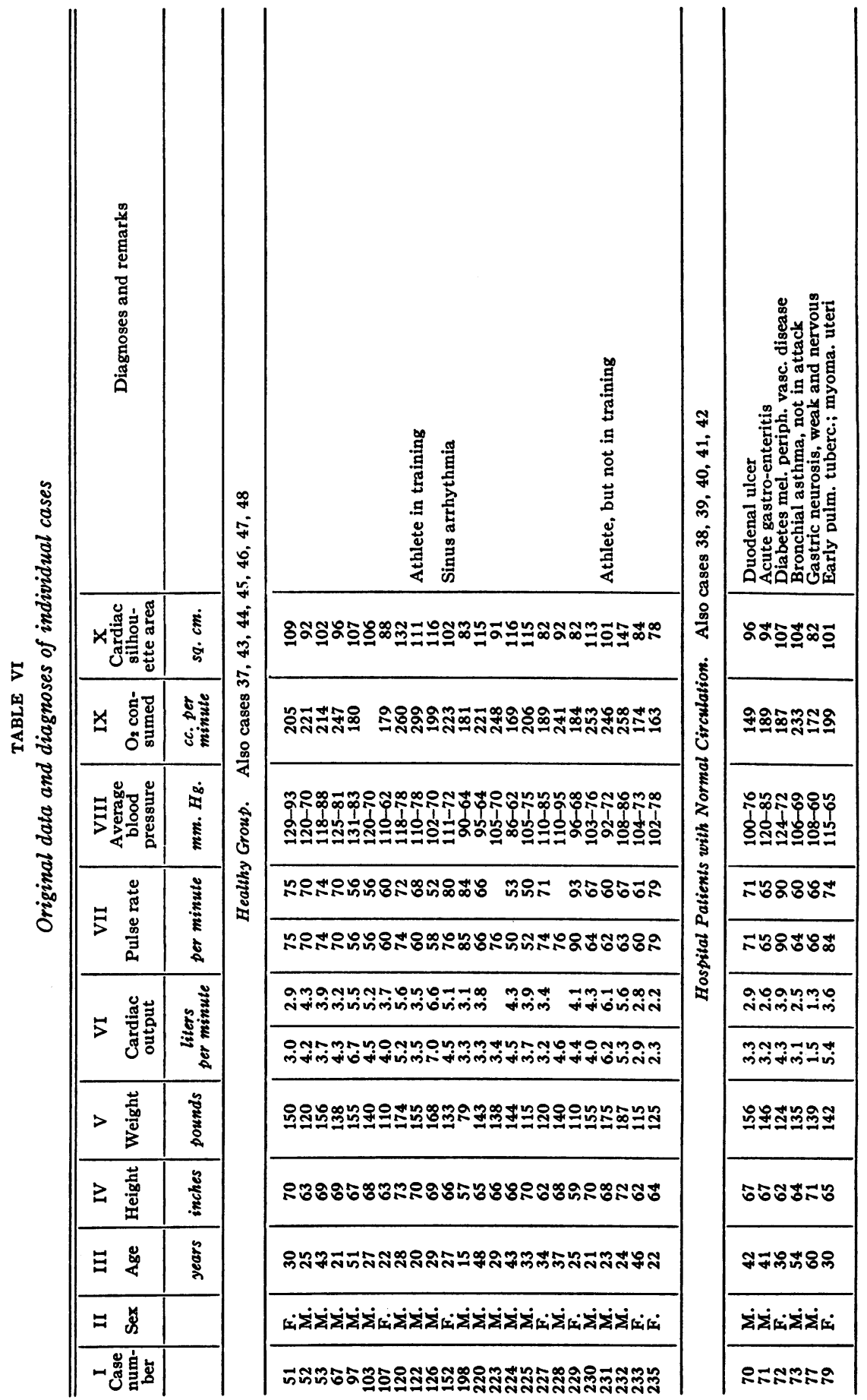



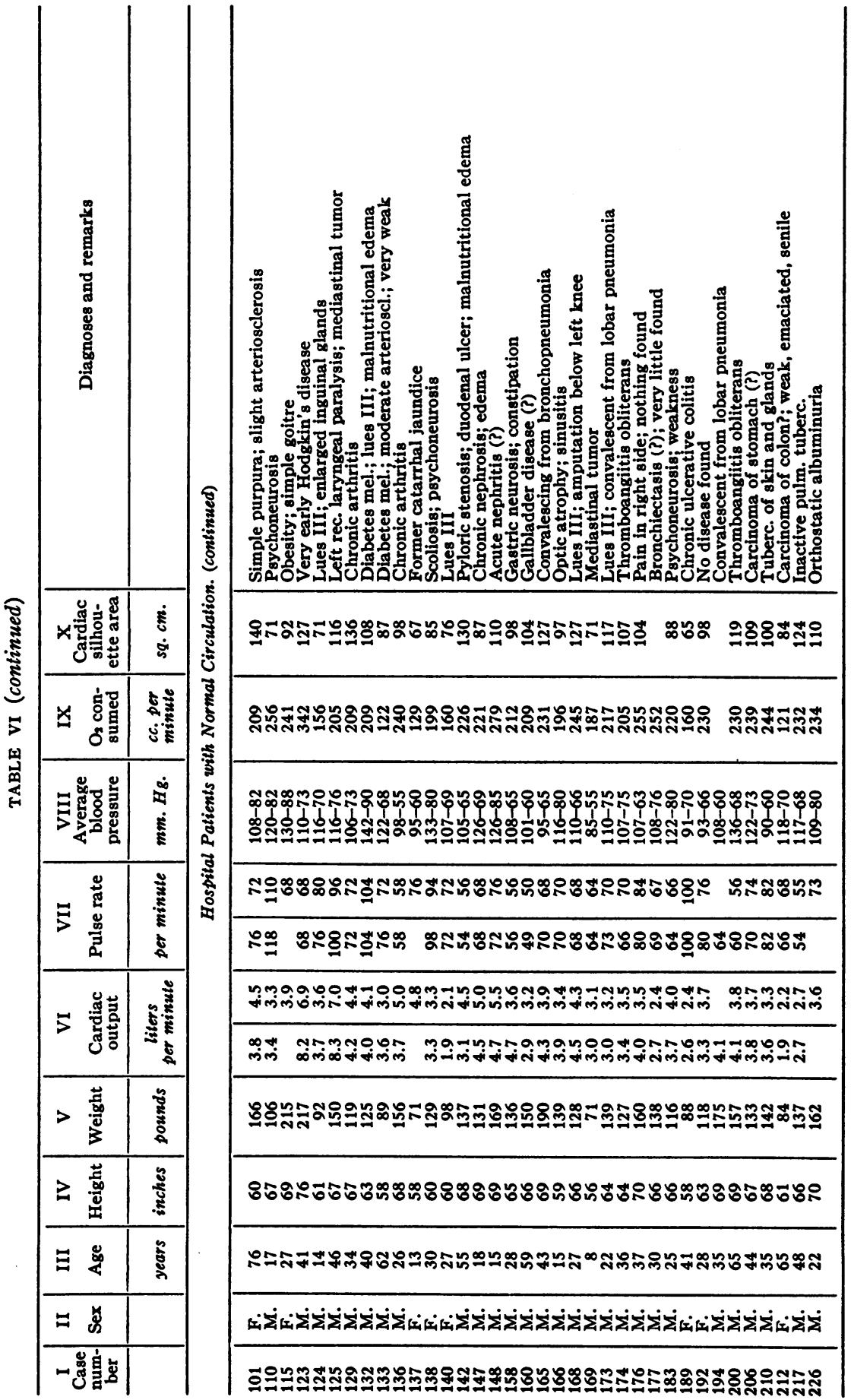


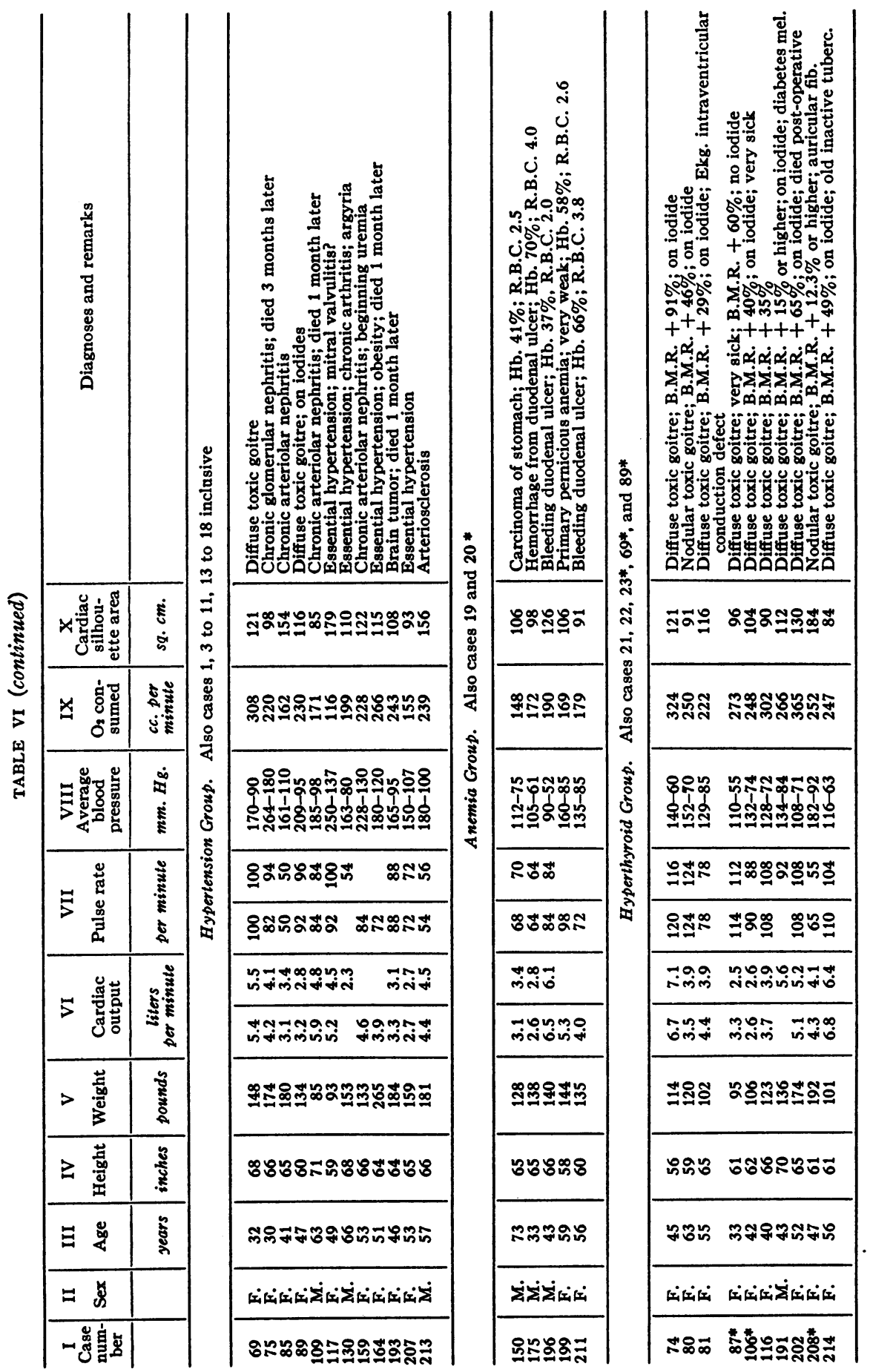


STARR, DONAL, MARGOLIES, SHAW, COLLINS AND GAMBLE

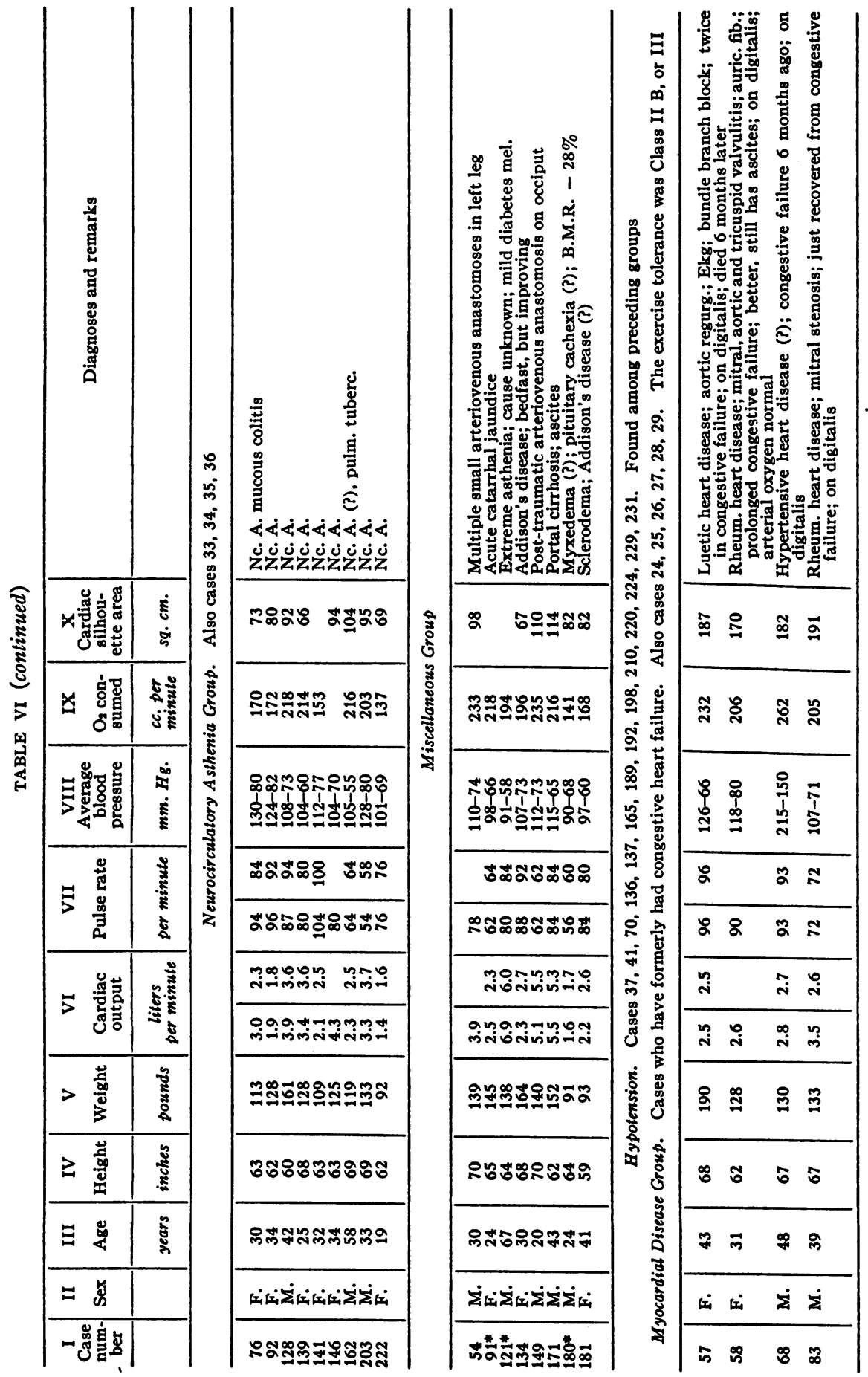




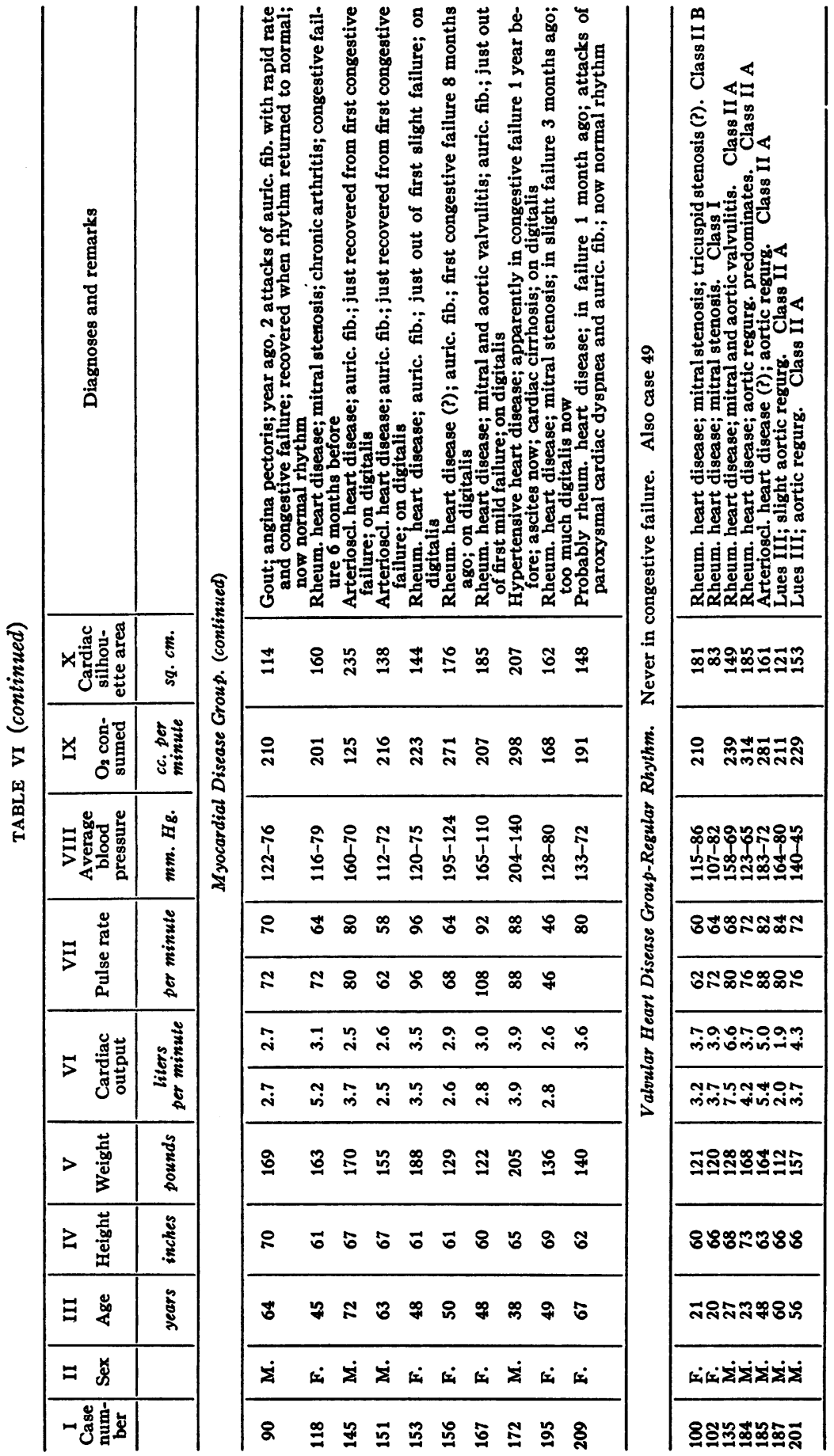


STARR, DONAL, MARGolies, SHAW, COLLINS AND GAMBLE 589

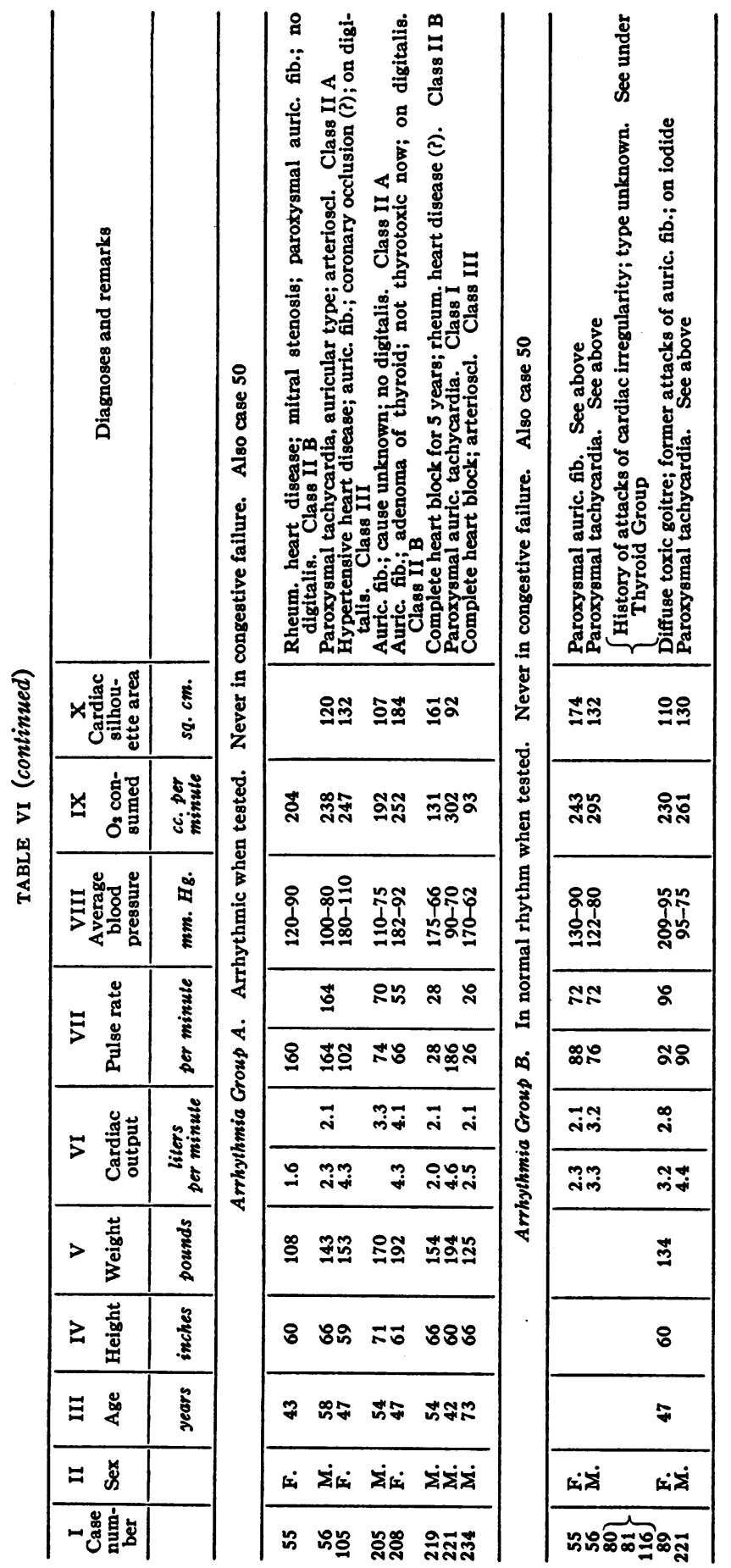




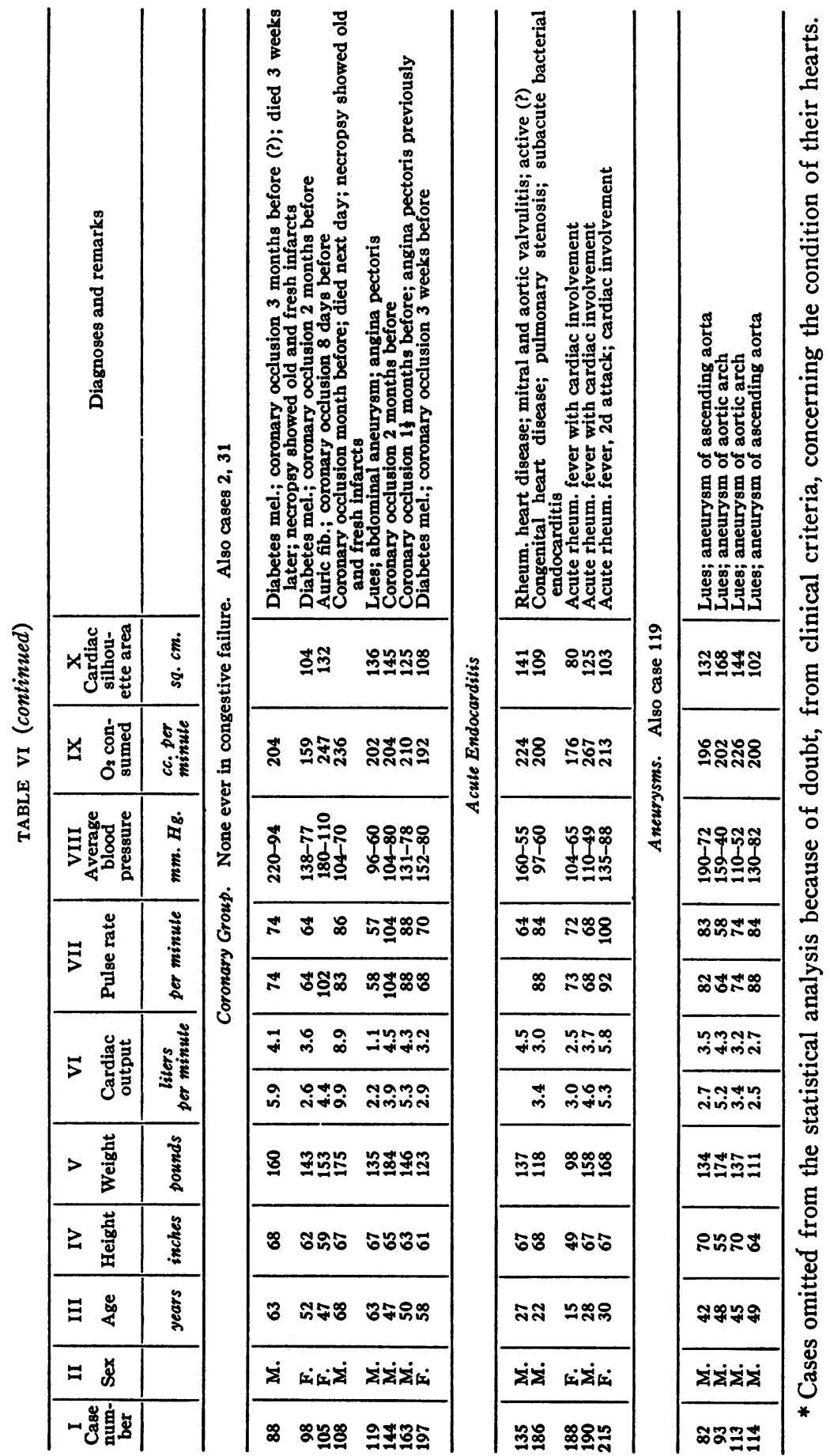




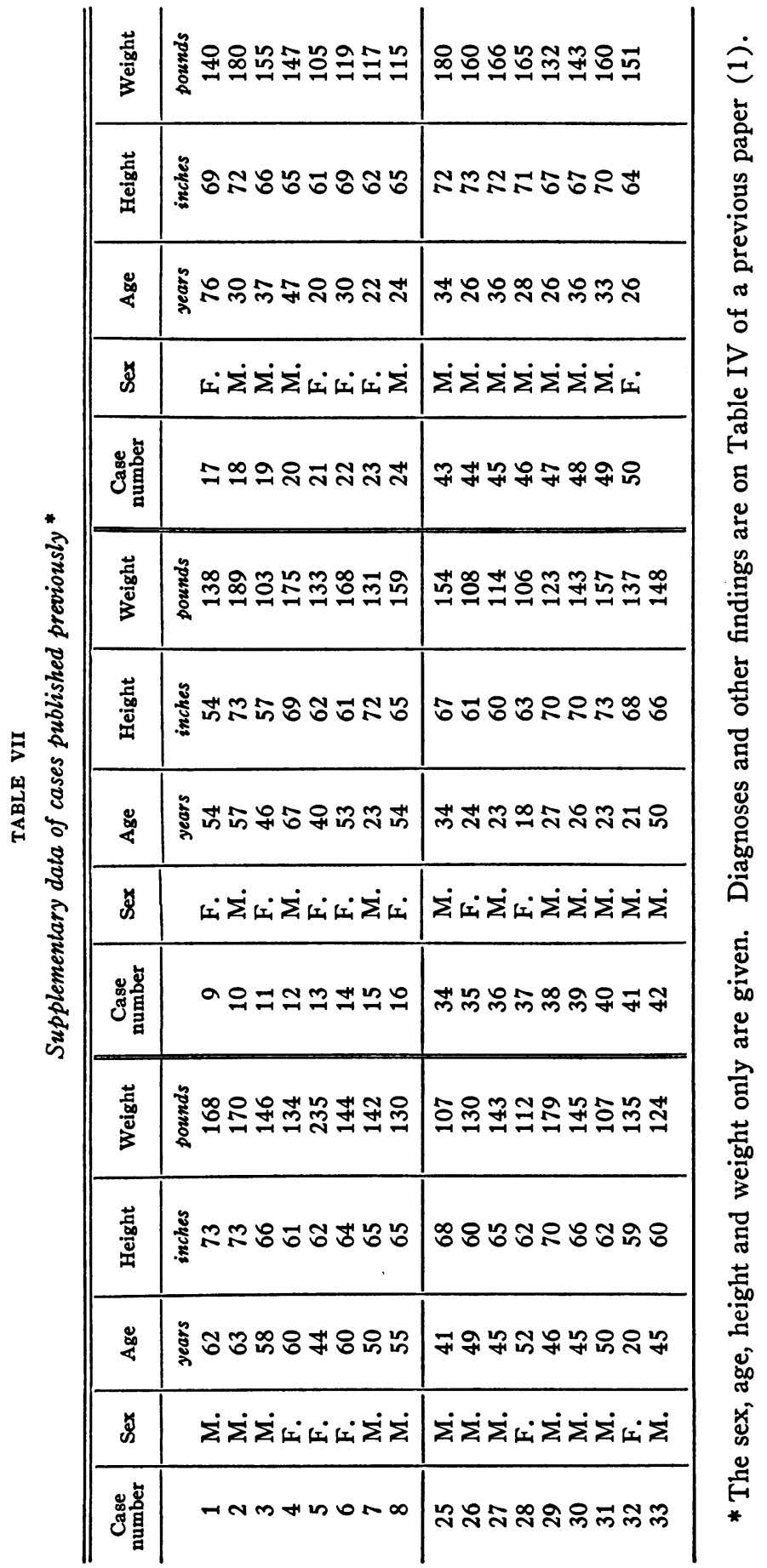




\section{BIBLIOGRAPHY}

1. Starr, I., Jr., Collins, L. H., Jr., and Wood, F. C., Studies of the basal work and output of the heart in clinical conditions. J. Clin. Invest., 1933, 12, 13.

2. Donal, J. S., Jr., and Gamble, C. J., The estimation of ethyl iodide by the katharometer in determinations of cardiac output in man. Am. J. Physiol., 1933, 105, 28. (Detailed description to be published.)

3. Grollman, A., The Cardiac Output of Man in Health and Disease. C. C. Thomas, Baltimore, 1932.

4. Starr, I., Jr., and Gamble, C. J., An improved method for the determination of cardiac output in man by means of ethyl iodide. Am. J. Physiol., $1928,87,450$.

5. Cool, R. D., Gamble, C. J., and Starr, I., Jr., The solubility of ethyl iodide in human blood and its correlation with the erythrocyte count. J. Biol. Chem., 1934, 105, 97.

6. Bardeen, C. R., Determination of the size of the heart by means of the $x-$ rays. Am. J. Anat., 1918, 23, 423.

7. Kahlstorf, A., Über Korrelationen der Linearen Herz Masse und des Herzvolumens. Klin. Wchnschr., 1933, 12, 262.

8. Dunn, H. L., Application of statistical methods in physiology. Physiol. Rev., 1929, 9, 275.

9. DuBois, E. F., c.f., Lusk, G., Science of Nutrition. W. B. Saunders, Philadelphia, 1917.

10. Lerman, J., and Means, J. H. Iodine in exophthalmic goitre. A comparison of the effect of ethyl iodid and potassium iodid with that of Lugol's solution. Am. J. M. Sc., 1931, 181, 745.

11. Wood, F. C., Bellet, S., McMillan, T. M., and Wolferth, C. C., Electrocardiographic study of coronary occlusion. Further observations on use of chest leads. Arch. Int. Med., 1933, 52, 752.

12. Fisher, R. A., Statistical Methods for Research Workers. Oliver and Boyd, Edinburgh, 1930, 3d ed.

13. Starling, E. H., The Linacre Lecture on the Law of the Heart. Longmans, Green and Co., London and New York, 1918.

14. Stewart, H. J., and Cohn, A. E., Studies on the effect of the action of digitalis on the output of blood from the heart. III. Part 1. The effect on the output in normal human hearts. Part 2. The effect on the output of hearts in heart failure with congestion, in human beings. J. Clin. Invest., 1932, 11, 917. 